\title{
BMJ Global Health Power and politics: the case for linking resilience to health system governance
}

\author{
Stephanie M Topp (1) ${ }^{1,2}$
}

To cite: Topp SM. Power and politics: the case for linking resilience to health system governance. BMJ Global Health 2020;5:e002891. doi:10.1136/ bmjgh-2020-002891

Received 12 May 2020 Accepted 14 May 2020

\section{Check for updates}

(c) Author(s) (or their employer(s)) 2020. Re-use permitted under CC BY-NC. No commercial re-use. See rights and permissions. Published by BMJ.

${ }^{1}$ College of Public Health, Medical and Veterinary Sciences, James Cook University, Townsville, Queensland, Australia ${ }^{2}$ Nossal Institute for Global Health, University of Melbourne, Parkville, Victoria, Australia

Correspondence to Dr Stephanie M Topp; globalstopp@gmail.com
Since the watershed moment of the 2014 Ebola epidemic in West Africa and again in the midst of the current COVID-19 crisis, the concept of health system resilience has been a recurring theme in global health discussions. ${ }^{12}$ Although most frequently used in the context of epidemic response, resilience has also been framed as a 'key pillar' of health, ${ }^{3}$ and invoked in high-level calls for countries to 'lead the work on building health system resilience'. Yet, as the authors of one of several recent reviews observed, the concept of health systems resilience remains 'highly confusing' and 'still polysemic'. ${ }^{5}$ What it means 'depends on one's perception, one's discipline, one's function and what one wants to achieve'. ${ }^{5}$ In this editorial, I will, from the perspective of a health policy and systems researcher, draw out and reflect on some of these tensions, and make some suggestions about how we might achieve greater clarity.

\section{WE SHOULD FRAME RESILIENCE AS AN ABILITY, NOT AN OUTCOME}

Building on the observations of Turenne $e t$ $a l$, the first point is definitional. In both peer reviewed and grey literature, there is still confusion about whether the concept of resilience (as it relates to health systems) should be understood as an outcome or an ability. This distinction is not semantic. Understood as an outcome, some in the field have suggested that health system resilience can and should be measured and monitored. ${ }^{6}$ By measuring resilience, it is argued, we can help to build more resilient health systems through identification of areas for action. ${ }^{78}$ But an important consequence of this framing is the implication that health system resilience is an uncomplicated, even monolithic 'good'; a goal synonymous with optimised performance. But a question that then arises is whether health systems that produce suboptimal health outcomes are somehow less resilient than those producing better ones?

The alternative framing of resilience as an ability, better aligns with the now broadly accepted observation that health systems and services are social, complex and adaptive in nature. ${ }^{9}$ When conceptualised in this way, enquiries about health system resilience focus more squarely on the dynamic nature of adaptation, without needing to make statements about the ends to which that adaptation occurs. This point is critical. History has demonstrated that health system adaptation may steer a system towards improved outcomes (normatively defined), but may equally worsen or protect less desirable features of health system function. These latter 'mal-adaptive' processes do not necessarily imply inactive or linear responses; individuals or groups may be highly innovative and willing to change in some areas, while seeking to, indeed often in order to, protect or preserve certain interests. As Gore observed in a study of primary healthcare in India, some systems appear to adapt in ways that ultimately 'sustain a deficient status quo $\cdot{ }^{10}$ Observers of the politics of healthcare in the USA over the past several decades may come to similar conclusions.

\section{DIFFERENT TYPES AND INTENSITIES OF SHOCK: DIFFERENT FORMS OF ADAPTATION}

A second and related point is about our understanding of the types and intensities of 'shocks' against which health systems are supposed to be resilient. We need to more clearly articulate the way: (1) health system shocks or disturbances occur on a spectrum of intensity, from acute and large-scale emergencies to low-level chronic stressors and (2) health system shocks or disturbances are the product of a range of different drivers or causal factors-which in turn have implications for the types of adaptation available and appropriate in response. As already pointed out by others, the use of the phrase 'resilient health systems' in global health literature still typically presupposes a positive response to some kind of large-scale negative shock such as the current COVID-19 epidemic outbreak, a budget crisis and so forth. 
But a burgeoning literature is starting to draw attention to the fact that health system disturbances may not necessarily be acute in nature. Gilson $e t a l^{11}$ and Barasa $e t a l^{12}$, for example, detail the 'chronic stressors' at the level of frontline health services, and describe 'everyday resilience' as emerging from a combination of absorptive, adaptive and transformative strategies that enable continued health service function in the face of such stressors.

But still largely ignored within the resilience literature is the possibility that shocks and disturbances arise out of intentional choices made by actors in international (eg, donor conditionalities; trade agreements), national (election promises; regulatory changes; austerity measures) or local (citizen voice mechanisms, organisational instability) spheres. Reforms to modes of governance, financing mechanisms or service delivery models, for example, are all forms of health system disturbance, capable of producing both intended and unintended consequences. Yet global health writing on resilience still rarely equates these bureaucratic, socially and politically driven changes with 'disturbances', perhaps due to their less sudden, more structured, and inherently political nature, features that do not align with our still default use of the term 'shock'. Nor, again outside a few notable pieces, have the political and bureaucratic responses to these intentional disturbances been acknowledged as a form of 'adaptation'.

\section{HEALTH SYSTEMS ARE SOCIAL SYSTEMS: SHOT THROUGH WITH POWER RELATIONS}

Which brings me to my third point on conceptual clarity; which is, to observe a previous criticism ${ }^{213-15}$ regarding the way resilience as a concept so often fails to incorporate consideration of agency or power relations, both of which we know to be defining features of health system function. In much of the health system resilience literature to date, the agency of actors within the health system is, at best blurred, and at worst, masked. With some few exceptions, the focus has tended to be on the ability of health systems to recover from shocks, with far less attention paid to the choices exercised by individuals or groups within the system, and the ways in which they do, or do not, exert control over processes by which that system-level resilience is shaped. ${ }^{16}$ In part, this is the natural consequence of transposing a concept originally developed with reference to ecosystems, onto social systems. Despite some commonalities these two types of systems retain key differences including that social systems 'embody power relations and do not involve analogies of being self-regulating or rational'. ${ }^{17}$ In scanning recent reviews of health system resilience it is interesting to note the general absence of mention of 'power' in the formulation of the concept. ${ }^{51819}$

\section{EXPLICITLY LINKING THE EXPLORATION OF HEALTH SYSTEM RESILIENCE TO HEALTH SYSTEM GOVERNANCE}

Clearer recognition of the full spectrum of disturbances (from exogenous epidemic-type shocks to political or bureaucratic stressors) in the context of social systems shot through with power, brings me to a final point. If global health researchers and practitioners are to continue to characterise health systems as social systems, then examination of their resilience (defined as an ability rather than an outcome) makes most sense when anchored to an exploration of the modes and dynamics of health system governance, at whichever level appropriate. As summarised by Blanchet $e t a l$, governance relates to the implicit and explicit rules and institutions that shape power, relationships between actors, and the actions of these actors, meaning that: "managing resilience of a health system resides in the capacity of managing actors, networks and institutions that have an influence on the health system,.${ }^{20}$ In other words, by taking governance as the point of departure for enquiries about health system resilience, we are consciously focusing on the actors and networks whose choices and actions we understand that resilience to depend.

Anchoring explorations of health systems resilience on governance provides a guide for considering both the explicit and implicit power dynamics, and the competing interests and goals, of various actors who we know impact all domains and levels of the health system. Such an approach does not preclude, but rather enables exploration of the characteristics of resilient health systems, with cross-disciplinary learning suggesting these characteristics are in any case actor-dependent, including for example: (1) diversity; (2) flexibility; (3) inclusion and participation; (4) recognition of social values; (4) acceptance of uncertainty and change at different levels and (5) and the ability to foster learning. ${ }^{17}$

Two examples of analyses using different methods to examine such issues have been recently published in $B M J$ Global Health. One is Saulnier et als account of health system resilience from the perspective of Cambodian communities responding to floods. ${ }^{21}$ This nuanced work reveals a range of strategies implemented by individuals, families and entire villages to mitigate the health access impacts of regular flood events, but demonstrates how those same actors have limited ability to build systemic resilience given their lack of decision making space or ownership of health system processes. Such a scenario, the authors observe, leaves 'the community vulnerable to more severe floods and different shocks' when their localised absorptive capacities fail. Here, we are reminded that what makes health systems resilient in the real world, may or may not depend on traditional supply side strategies (indeed it may be in spite of such). More disturbingly, we see too that resilience may not in fact enable high quality or equitable health services for vulnerable populations but rather, in Gore's words, underpin a deficient status quo.

Lee $e t$ al in their article "How coping can hide larger systems problems: the routine immunisation supply chain in Bihar, India"22 identify how persistent "coping behaviours' by front-line health workers in aid of routine immunisation, mask systemic deficiencies in the cold 
chain policy and logistics of that state. While coping behaviours may on the surface be seen as a form of resilience, the authors demonstrate how long term reliance on such behaviours is likely to contribute to systemic brittleness, not resilience, since: 'one set of personnel, those at the outermost level [...] bear a disproportionate burden in supporting the system, leaving them overstretched and in a potentially very unstable situation. If circumstances were to further change or these personnel are no longer able to cope, the entire system could break down very quickly. ${ }^{22}$ The authors make the critical, if somewhat counterintuitive observation, that instituting 'anticoping measures' and encouraging a culture in which coping is discouraged may be necessary to redress broader and deeper system-related dysfunction.

The above two articles highlight a critical distinction between asking whether the health system has the ability to respond to, and learn from, a change or disturbance, and an assessment of who or what benefits from that adaptation in the short and longer term. If we do not ask the latter ('who benefits from adaptation?') we risk conflating the pursuit of resilience with the pursuit of improvements in health and equity. Put bluntly, the capacity to adapt and implied resilience it conveys become equally or more important than whether that adaptation and resilience produces improved health.

And in this, there is a further risk: that resilience is used to help push for the adoption of policies that ultimately undermine high quality or equitable systems or which contract the space available for debating such alternatives. ${ }^{17}$ The linking of resilience to health security agendas, for example, can be used to divert public attention away from existing deeply embedded health inequities and the conscious choices that shape our (often inadequate) health system responses to them, in favour anticipating how, where, and when health emergencies will happen (ie, preparation), and what sorts of responses are pragmatic and acceptable in those extreme circumstances (ie, adaptation and resilience). ${ }^{2}$ The danger of the concept of resilience being thus mobilised is greater, moreover, in the midst or immediate aftermath of dramatic systemic shocks, such as the 2014 Ebolavirus epidemic and the current COVID-19 pandemic.

\section{CONCLUSION}

For global health and health systems researchers and practitioners, the concept of resilience has utility, including for its ability to frame health-related challenges within a systemic approach; accounting for different types of disturbance or shock, multiple actors, dynamic processes and feedback loops occurring across different domains and levels of the health system. But resilience in health systems should not be seen as an apolitical outcome, synonymous with a strong health systems or improved population health. What promotes the ability of a health system to be resilient must be assessed in the context of the interests and intentions of health system actors and the ways in which they mobilise and channel their power. Not to do so risks allowing some abstract conception of 'health system resilience' to, intentionally or unintentionally, displace attention and efforts away from the sorts of reforms necessary to address and improve long-standing health inequities. In current COVID-19 context, we must be particularly alert to such risks.

Twitter Stephanie M Topp @globalstopp

Acknowledgements SMT acknowledges Kerry Scott, Veena Sriram and Seye Abimbola for their review and feedback during the formulation of this article.

Contributors SMT conceived and wrote this editorial.

Funding SMT is currently supported through a National Health and Medical Research Council (NHMRC) Investigator Grant (GNT1173004).

Competing interests None declared.

Patient consent for publication Not required.

Provenance and peer review Not commissioned; internally peer reviewed.

Data availability statement There are no data in this work.

Open access This is an open access article distributed in accordance with the Creative Commons Attribution Non Commercial (CC BY-NC 4.0) license, which permits others to distribute, remix, adapt, build upon this work non-commercially, and license their derivative works on different terms, provided the original work is properly cited, appropriate credit is given, any changes made indicated, and the use is non-commercial. See: http://creativecommons.org/licenses/by-nc/4.0/.

ORCID iD

Stephanie M Topp http://orcid.org/0000-0002-3448-7983

\section{REFERENCES}

1 Haldane V, Ong S-E, Chuah FL-H, et al. Health systems resilience: meaningful construct or catchphrase? Lancet 2017;389:1513.

2 Abimbola S, Topp SM. Adaptation with robustness: the case for clarity on the use of 'resilience' in health systems and global health. BMJ Glob Health 2018;3:e000758.

3 WHO European Regional Office, Ziglio E. Strengthening resilience: a priority shared by health 2020 and the sustainable development goals. Denmark: WHO, 2017. http://www.euro.who.int/_data/ assets/pdf_file/0005/351284/resilience-report-20171004-h1635.pdf

4 World Health Organization. High level meeting on building resilient systems for health in Ebola-affected countries. Geneva: World Health Organization, 2014. https://www.who.int/csr/resources/publications/ ebola/hs-meeting.pdf?ua $=1$

5 Turenne CP, Gautier L, Degroote S, et al. Conceptual analysis of health systems resilience: a scoping review. Soc Sci Med 2019;232:168-80.

6 Kruk ME, Ling EJ, Bitton A, et al. Building resilient health systems: a proposal for a resilience index. BMJ 2017;357:j2323.

7 Odhiambo J, Jeffery C, Lako R, et al. Measuring health system resilience in a highly fragile nation during protracted conflict: South Sudan 2011-15. Health Policy Plan 2020;35:313-22.

8 Naimoli JF, Saxena S. Realizing their potential to become learning organizations to foster health system resilience: opportunities and challenges for health ministries in low- and middle-income countries. Health Policy Plan 2018;33:1083-95.

9 Greenhalgh T, Papoutsi C. Studying complexity in health services research: desperately seeking an overdue paradigm shift. BMC Med 2018;16:95.

10 Gore R. The power of popular opinion in everyday primary care provision in urban India. Glob Public Health 2019;14:528-41.

11 Gilson L, Barasa E, Nxumalo N, et al. Everyday resilience in district health systems: emerging insights from the front lines in Kenya and South Africa. BMJ Glob Health 2017;2:e000224.

12 Barasa EW, Cloete K, Gilson L. From bouncing back, to nurturing emergence: reframing the concept of resilience in health systems strengthening. Health Policy Plan 2017;32:iii91-4.

13 Hanefeld J, Mayhew S, Legido-Quigley H, et al. Towards an understanding of resilience: responding to health systems shocks. Health Policy Plan 2018;33:355-67. 
14 van de Pas R, Ashour M, Kapilashrami A, et al. Interrogating resilience in health systems development. Health Policy Plan 2017;32:iii88-90.

15 Young OR, Berkhout F, Gallopin GC, et al. The globalization of socioecological systems: an agenda for scientific research. Glob Environ Change 2006;16:304-16.

16 Coulthard S. Can we be both resilient and well, and what choices do people have? incorporating agency into the resilience debate from a fisheries perspective. Ecol Soc 2012;17.

17 Bene C, Godfrey Wood R, Newsham A, et al. Resilience: new utopia of new tyranny? reflection about the potentials and limits of the concept of resilience in relation to vulnerability reduction programmes. Sussex: Institute of Development Studies, 2012.

18 Barasa E, Mbau R, Gilson L. What is resilience and how can it be Nurtured? A systematic review of empirical literature on organizational resilience. Int J Health Policy Manag 2018;7:491-503.
19 Nuzzo JB, Meyer D, Snyder M, et al. What makes health systems resilient against infectious disease outbreaks and natural hazards? Results from a scoping review. BMC Public Health 2019;19:1310.

20 Blanchet K, Nam SL, Ramalingam B, et al. Governance and capacity to manage resilience of health systems: towards a new conceptual framework. Int J Health Policy Manag 2017;6:431-5.

21 Saulnier DD, Hean H, Thol D, et al. Staying afloat: community perspectives on health system resilience in the management of pregnancy and childbirth care during floods in Cambodia. BMJ Glob Health 2020;5:e002272.

22 Lee BY, Wedlock PT, Mitgang EA, et al. How coping can hide larger systems problems: the routine immunisation supply chain in Bihar, India. BMJ Glob Health 2019;4:e001609. 